\title{
Perspective
}

PERSPECTIVE Actualité en histoire de l'art

Comptes rendus | 2011

\section{Cynthia Gamble, Matthieu Pinette, L'CFil de Ruskin : l'exemple de la Bourgogne, Dijon, Les Presses du Réel, 2011}

\section{Rémi Labrusse}

\section{(2) OpenEdition \\ Journals}

Édition électronique

URL : http://journals.openedition.org/perspective/3360

DOI : $10.4000 /$ perspective. 3360

ISSN : 2269-7721

Éditeur

Institut national d'histoire de l'art

Référence électronique

Rémi Labrusse, "Cynthia Gamble, Matthieu Pinette, L'EFil de Ruskin : l'exemple de la Bourgogne, Dijon, Les Presses du Réel, $2011 »$, Perspective [En ligne], Comptes rendus, mis en ligne le 03 septembre 2013, consulté le 01 octobre 2020. URL : http://journals.openedition.org/perspective/3360 ; DOI : https://doi.org/10.4000/perspective.3360

Ce document a été généré automatiquement le 1 octobre 2020. 


\section{Cynthia Gamble, Matthieu Pinette,} L'Eil de Ruskin : l'exemple de la Bourgogne, Dijon, Les Presses du Réel, 2011

Rémi Labrusse

\section{RÉFÉRENCE}

Cynthia Gamble, Matthieu Pinette, L'Æiil de Ruskin : l'exemple de la Bourgogne, Dijon, Les Presses du Réel, 2011. 
1 Tous les moyens sont bons pour donner vie en français à l'œuvre de Ruskin, continent aussi vaste que labyrinthique qui touche, comme on sait, aussi bien à la peinture et à l'architecture qu'à la théorie du patrimoine et aux arts décoratifs, et qui entrelace toujours esthétique, morale et politique. Parmi les deux livres publiés en 2011 par les Presses du réel, le premier, L'CEil de Ruskin: l'exemple de la Bourgogne, est largement composé d'extraits réunis par Cynthia Gamble et Matthieu Pinette, dans lesquels Ruskin a noté ses impressions bourguignonnes au cours de la quinzaine de séjours qu'il a faits entre 1833 et 1888 dans cette région - à mi-chemin entre ses destinations préférées de la Picardie et de Venise. L'intérêt documentaire est d'autant plus grand que les choix de l'écrivain se portent bien souvent sur des villes et des détails - telle fenêtre de maison bourgeoise d'un quartier de Châtillon-sur-Seine, minutieusement analysée et dessinée - à l'écart des grands itinéraires touristiques. Mais, au-delà, c'est le passage incessant du local à l'universel, dans ces notations, qui fait pleinement du livre une entrée à la fois singulière et authentique au cœur du système Ruskin. 